\title{
Fixed scattering section length with variable scattering section dispersion based optical fibers for polarization mode dispersion penalties
}

\author{
Mahmoud M. A. Eid ${ }^{1}$, Ahmed Nabih Zaki Rashed ${ }^{2}$ \\ ${ }^{1}$ Department of Electrical Engineering, College of Engineering, Taif University, Kingdom of Saudi Arabia, \\ ${ }^{2}$ Electronics and Electrical Communications Engineering Department Faculty of Electronic Engineering, Menoufia \\ University, Egypt
}

\begin{tabular}{|c|c|}
\hline Article Info & ABSTRACT \\
\hline Article history: & This study has clarified the fixed scattering section length with variable \\
\hline Received Apr 15, 2020 & $\begin{array}{l}\text { scattering section dispersion based optical fibers for polarization mode } \\
\text { dispersion penalties at high data rates. The max signal power/min. noise }\end{array}$ \\
\hline Revised Jun 7, 2020 & power is simulated against time after fiber length of $500 \mathrm{~km}$ with various \\
\hline Accepted Jun 15, 2020 & $\begin{array}{l}\text { scattering section dispersion. The overall total light power is simulated after } \\
\text { fiber length of } 500 \mathrm{~km} \text { with various scattering section dispersion. In addition }\end{array}$ \\
\hline Keywords: & $\begin{array}{l}\text { to the overall total electrical power is clarified through APD receiver at fiber } \\
\text { length of } 500 \mathrm{~km} \text { with various scattering section dispersion. Eye diagram }\end{array}$ \\
\hline Dispersion penalties & analyzer for signal quality is also simulated through APD receiver at fiber \\
\hline Fixed scattering length & $\begin{array}{l}\text { length of } 500 \mathrm{~km} \text { with various scattering section dispersion. The } \max \mathrm{Q} \\
\text { factor electrical signal power after APD receiver variations against }\end{array}$ \\
\hline Polarization mode dispersion & scattering section dispersion variations for various data rates. \\
\hline RZ code & \\
\hline
\end{tabular}

This is an open access article under the CC BY-SA license.

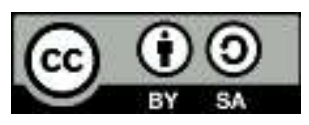

Corresponding Author:

Ahmed Nabih Zaki Rashed

Faculty of Electronic Engineering

Menouf 32851, Menoufia University, Egypt

E-mail: ahmed_733@yahoo.com

\section{INTRODUCTION}

Polarization mode dispersion (PMD) in optical channels has been a critical factor limiting highspeed data transmission over long distances in optical networks. PMD is a source of inter symbol interference (ISI) and its impact increases with the transmission data rate [1-5]. Since economical adaptive compensation schemes are currently unavailable, it is essential to characterize this impairment to completely understand its impact and develop effective countermeasures [6-10].

Optical fiber impairments are critical factors limiting high-speed data transmission over long distances in optical communication networks. Impairments in the channel caused by chromatic dispersion and transmission loss have a direct impact on the reach of a network or the quality of transmission at higher bit rates and narrowly spaced channels/the presence of PMD in optical fibers is one of the main factors limiting the capability of a channel to transport high-speed data [11-16]. PMD reduces the reach of networks, and the increased regeneration requirements of optical signals result in expensive network designs [17-22].

To compensate for the degradation in the optical signal caused by these effects the signal may require reconstruction and regeneration over the length of transmission [23-25]. The receiver section detects the optical signal, and the modulated information is recovered. The performance of such a typical optical network configuration is primarily a function of the system components and the transmission media [26-35]. 


\section{MODEL DESCRIPTION AND RESEARCH METHOD}

Figure 1 clarifies the data bit stream sequences can be encoded with the return to zero coding which represent the first input electrical encoded signal for the electro optic $\mathrm{LiNbO}_{3}$ modulators. The second input to the modulators is from the continuous wave laser. The third input is the encoded RZ scheme for the bit stream sequence. The laser frequency is $195 \mathrm{THz}$, laser power is $5 \mathrm{dBm}$. The modulated signal reaches to the optical fiber medium.

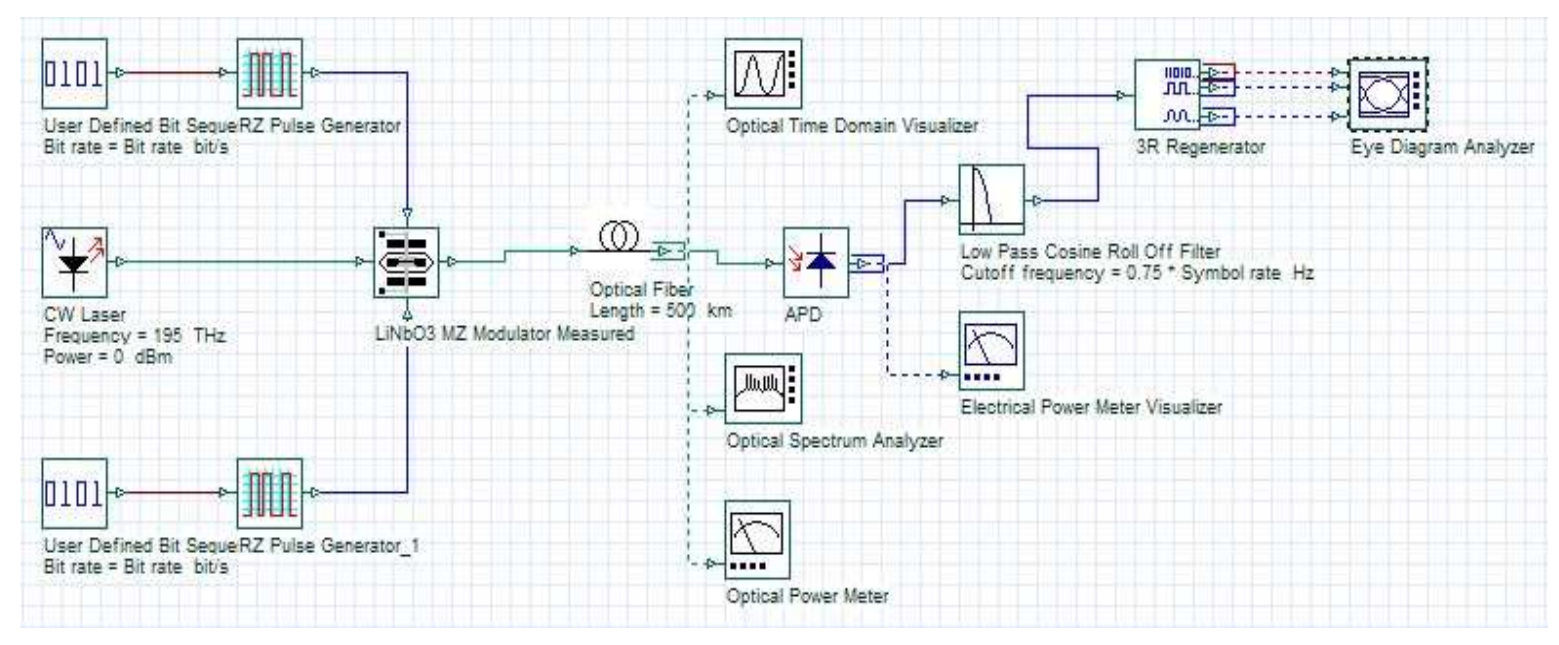

Figure 1. Model simulation description for the study

The optical fiber has a length of $500 \mathrm{~km}$, mean scattering section length of $10000 \mathrm{~m}$, average scattering section dispersion of $50 \mathrm{~m}$, attenuation of $0.2 \mathrm{~dB} / \mathrm{km}$. The optical power versus spectral frequency and time domain are measured. The overall total light power is also measured by optical power meter. The light signal can be converted to the electrical signal by avalanche photodiode (APD) receiver. All the unwanted high frequency signals and ripples can be eliminated by low pass bessel filter. The max Q factor and min. BER can be evaluated and measured by eye diagram analyzers.

\section{PERFORMANCE ANALYSIS WITH DISCUSSIONS}

The overall total light power is simulated after fiber length of $500 \mathrm{~km}$ with various scattering section dispersion. In addition to the overall total electrical power is clarified through APD receiver at fiber length of $500 \mathrm{~km}$ with various scattering section dispersion. Eye diagram analyzer for signal quality is also simulated through APD receiver at fiber length of $500 \mathrm{~km}$ with various scattering section dispersion. The max Q Factor, electrical signal power after APD receiver variations against scattering section dispersion variations for various data rates. Figures 2-4 clarify the max signal power/min. noise power against time after fiber length of $500 \mathrm{~km}$ with various scattering section dispersion. Figure 2 shows the max signal power/min. noise power against time after fiber length $(500 \mathrm{~km})$ with scattering section dispersion of $10 \mathrm{~m}$. Where the max signal power is $0.0012824 \mathrm{~W}$, min. noise power is $-6.1 \times 10^{-5} \mathrm{~W}$. Figure 3 indicates the max signal power/min. noise power against time after fiber length $(500 \mathrm{~km})$ with scattering section dispersion of $50 \mathrm{~m}$. Where the max signal power is $0.0012663 \mathrm{~W}$, min. noise power is $-6.0298 \times 10^{-5} \mathrm{~W}$. Figure 4 clarifies the max signal power/min. noise power against time after fiber length $(500 \mathrm{~km})$ with scattering section dispersion of $100 \mathrm{~m}$. Where the max signal power is $0.0012532 \mathrm{~W}$, min. noise power is $-5.9674 \times 10^{-5} \mathrm{~W}$. It is indicated that the increase of scattering section dispersion, this results in the decrease of the max signal power.

Figure 5 show the max signal power/min. noise power against spectral wavelength after fiber length $(500 \mathrm{~km})$ with scattering section dispersion of $10 \mathrm{~m}, 50 \mathrm{~m}, 100 \mathrm{~m}$. The study emphasized the max signal power is $-6.55966 \mathrm{dBm}$ and min. noise power is $-90.254 \mathrm{dBm}$ at all values of scattering section dispersion. So the max signal power/min. noise power are the same values at all values of scattering section dispersion. Figure 6 illustrates the overall total light power after fiber length $(500 \mathrm{~km})$ with scattering section dispersion of $10 \mathrm{~m}, 50 \mathrm{~m}, 100 \mathrm{~m}$. The optical power is $296.172 \mu \mathrm{W}$ or $-5.285 \mathrm{dBm}$ at all values of scattering section dispersion. So the optical power is the same values at all values of scattering section dispersion.

Figure 7 demonstrates the overall total electrical power through APD receiver at fiber length (500 $\mathrm{km}$ ) with scattering section dispersion of $10 \mathrm{~m}, 50 \mathrm{~m}, 100 \mathrm{~m}$. The electrical power is $2.356 \mu \mathrm{W}$ or -26.279 
$\mathrm{dBm}$ at all values of scattering section dispersion. So the electrical power is the same values at all values of scattering section dispersion.

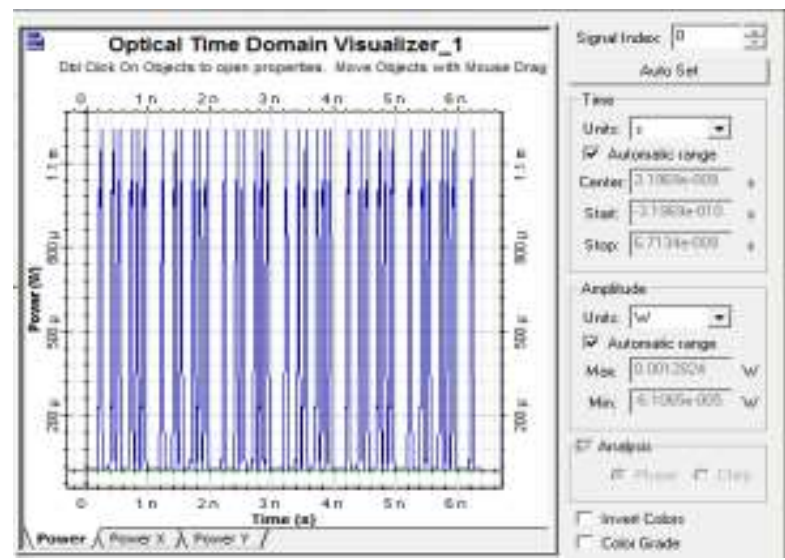

Figure 2. Max signal power/min noise power against time after fiber length $(500 \mathrm{~km})$ with scattering section dispersion of $10 \mathrm{~m}$

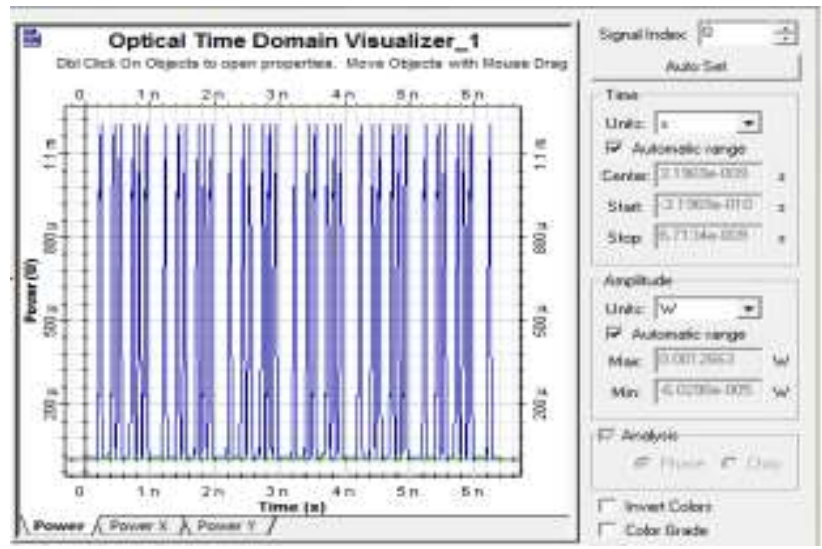

Figure 3. Max signal power/min noise power against time after fiber length $(500 \mathrm{~km})$ with scattering section dispersion of $50 \mathrm{~m}$

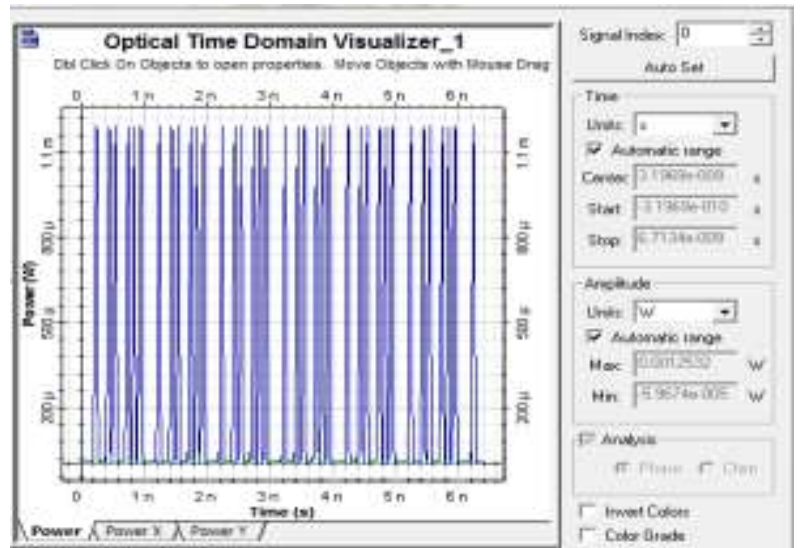

Figure 4. Max signal power/min. noise power against time after fiber length $(500 \mathrm{~km})$ with scattering section dispersion of $100 \mathrm{~m}$ 

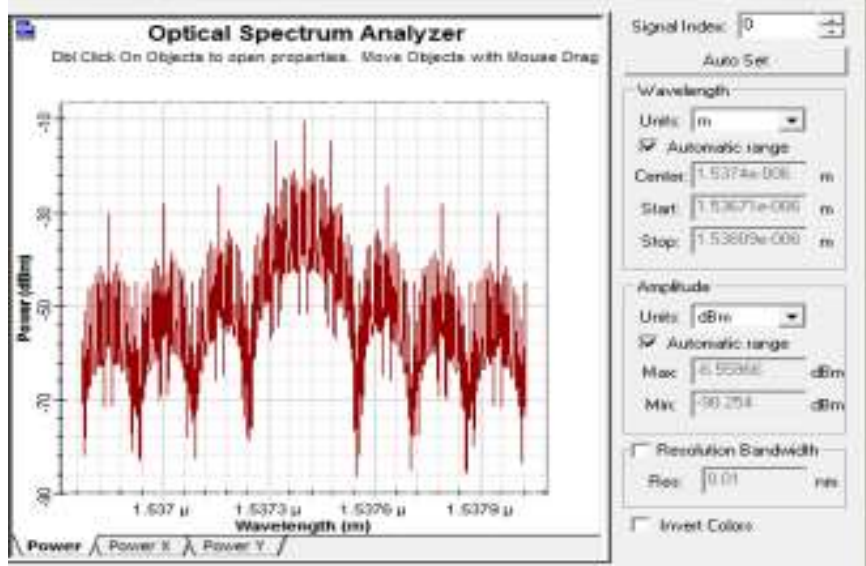

Figure 5. Max signal power/min noise power against spectral wavelength after fiber length (500 km) with scattering section dispersion of $10 \mathrm{~m}, 50 \mathrm{~m}, 100 \mathrm{~m}$

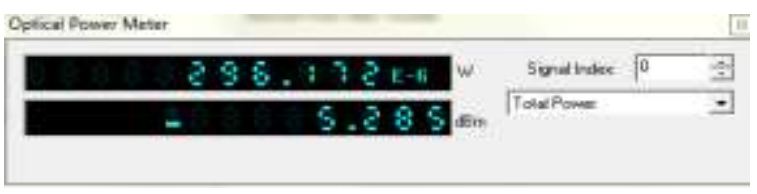

Figure 6. Overall total light power after fiber length $(500 \mathrm{~km})$ with scattering section dispersion of $10 \mathrm{~m}$, $50 \mathrm{~m}, 100 \mathrm{~m}$

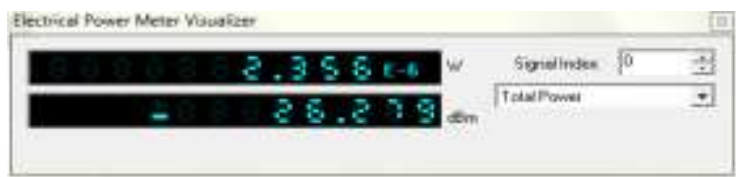

Figure 7. Overall total electrical power through APD receiver at fiber length $(500 \mathrm{~km})$ with scattering section dispersion of $10 \mathrm{~m}, 50 \mathrm{~m}, 100 \mathrm{~m}$

Figures 8-10 illustrate the eye diagram analyzer for signal quality through APD receiver at fiber length $(500 \mathrm{~km})$ with various scattering section dispersion. Figure 8 clarifies the eye diagram analyzer for signal quality through APD receiver at fiber length $(500 \mathrm{~km})$ with scattering section dispersion of $10 \mathrm{~m}$. Where the max Q Factor is 279.592, min. bit error rate tends to zero. Figure 9 indicates the eye diagram analyzer for signal quality through APD receiver at fiber length $(500 \mathrm{~km})$ with scattering section dispersion of $50 \mathrm{~m}$. Where the max Q Factor is 282.513, min bit error rate tends to zero. In addition to Figure 10 demonstrates the eye diagram analyzer for signal quality through APD receiver at fiber length $(500 \mathrm{~km})$ with scattering section dispersion of $100 \mathrm{~m}$. Where the max Q Factor is 284.682, min bit error rate tends to zero. The max $\mathrm{Q}$ factor is upgraded with the increase of the scattering section dispersion. This is the reason that with the higher the scattering section dispersion, the lower bit rate and consequently the higher signal quality factor.

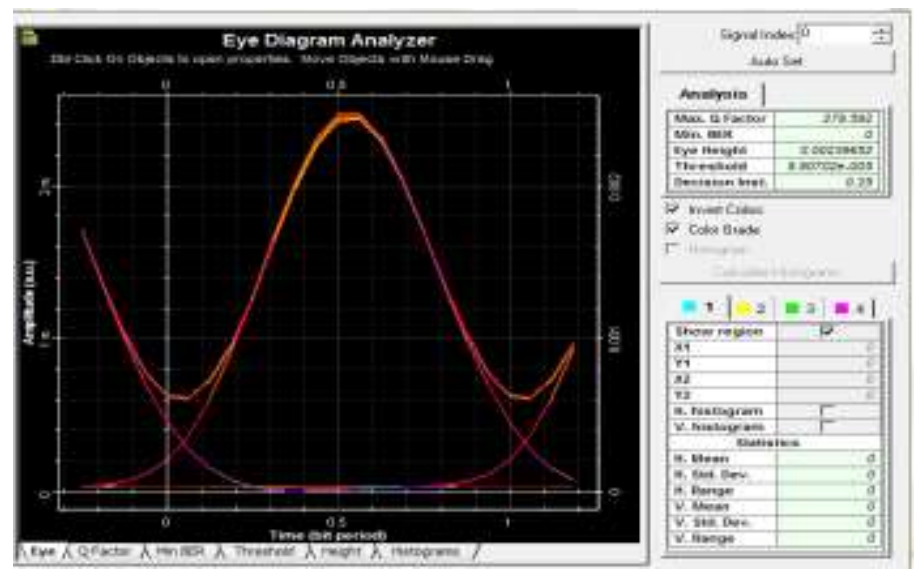

Figure 8. Eye diagram analyzer for signal quality through APD receiver at fiber length $(500 \mathrm{~km})$ with scattering section dispersion of $10 \mathrm{~m}$ 


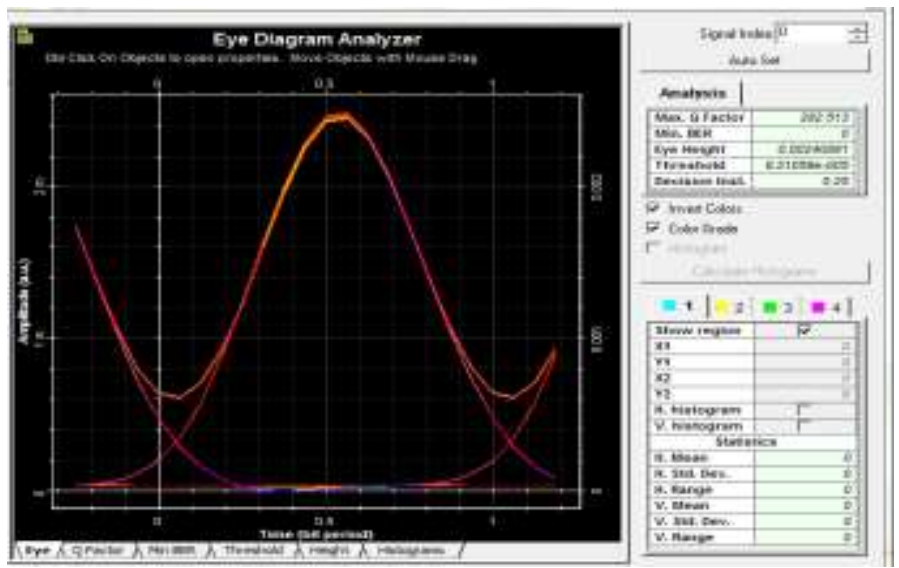

Figure 9. Eye diagram analyzer for signal quality through APD receiver at fiber length $(500 \mathrm{~km})$ with scattering section dispersion of $50 \mathrm{~m}$

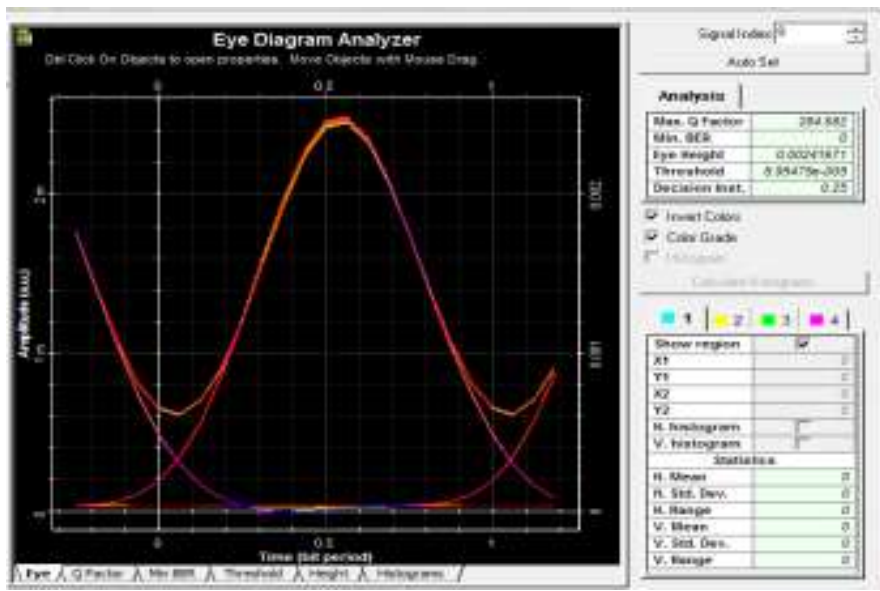

Figure 10. Eye diagram analyzer for signal quality through APD receiver at fiber length $(500 \mathrm{~km})$ with scattering section dispersion of $100 \mathrm{~m}$

Figure 11 shows the max Q Factor variations versus scattering section dispersion variations for various data rates. The max $\mathrm{Q}$ factor is $279.5,165,106,76,15.39$ at $10 \mathrm{~Gb} / \mathrm{s}, 40 \mathrm{~Gb} / \mathrm{s}, 100 \mathrm{~Gb} / \mathrm{s}, 160 \mathrm{~Gb} / \mathrm{s}$, $250 \mathrm{~Gb} / \mathrm{s}$ respectively at $10 \mathrm{~m}$ scattering section dispersion. The max $\mathrm{Q}$ factor is $282.5,168,109,78,17.22$ at $10 \mathrm{~Gb} / \mathrm{s}, 40 \mathrm{~Gb} / \mathrm{s}, 100 \mathrm{~Gb} / \mathrm{s}, 160 \mathrm{~Gb} / \mathrm{s}, 250 \mathrm{~Gb} / \mathrm{s}$ respectively at $50 \mathrm{~m}$ scattering section dispersion. While the $\max Q$ factor is $284.65,171,112,80,19.87$ at $10 \mathrm{~Gb} / \mathrm{s}, 40 \mathrm{~Gb} / \mathrm{s}, 100 \mathrm{~Gb} / \mathrm{s}, 160 \mathrm{~Gb} / \mathrm{s}, 250 \mathrm{~Gb} / \mathrm{s}$ respectively at $100 \mathrm{~m}$ scattering section dispersion. The max Q factor is $287,174,115,82,21.2$ at $10 \mathrm{~Gb} / \mathrm{s}, 40 \mathrm{~Gb} / \mathrm{s}, 100$ $\mathrm{Gb} / \mathrm{s}, 160 \mathrm{~Gb} / \mathrm{s}, 250 \mathrm{~Gb} / \mathrm{s}$ respectively at $150 \mathrm{~m}$ scattering section dispersion. Moreover the max $\mathrm{Q}$ factor is $290,177,118,84,23.7$ at $10 \mathrm{~Gb} / \mathrm{s}, 40 \mathrm{~Gb} / \mathrm{s}, 100 \mathrm{~Gb} / \mathrm{s}, 160 \mathrm{~Gb} / \mathrm{s}, 250 \mathrm{~Gb} / \mathrm{s}$ respectively at $200 \mathrm{~m}$ scattering section dispersion. The max Q factor is $292.85,180,121,87,25.767$ at $10 \mathrm{~Gb} / \mathrm{s}, 40 \mathrm{~Gb} / \mathrm{s}, 100 \mathrm{~Gb} / \mathrm{s}, 160$ $\mathrm{Gb} / \mathrm{s}, 250 \mathrm{~Gb} / \mathrm{s}$ respectively at $250 \mathrm{~m}$ scattering section dispersion. The results emphasized that the higher the scattering section dispersion the high the max $\mathrm{Q}$ factor.

Figure 12 demonstrates the electrical signal power after APD receiver variations versus scattering section dispersion variations for various data rates. The electrical power is $2.356 \mu \mathrm{W}, 1.5 \mu \mathrm{W}, 1.365 \mu \mathrm{W}$, $1.186 \mu \mathrm{W}, 1 \mu \mathrm{W}$ at $10 \mathrm{~Gb} / \mathrm{s}, 40 \mathrm{~Gb} / \mathrm{s}, 100 \mathrm{~Gb} / \mathrm{s}, 160 \mathrm{~Gb} / \mathrm{s}, 250 \mathrm{~Gb} / \mathrm{s}$ respectively at $10 \mathrm{~m}$ scattering section dispersion. The electrical power is $2.354 \mu \mathrm{W}, 1.427 \mu \mathrm{W}, 1.341 \mu \mathrm{W}, 1.1 \mu \mathrm{W}, 0.965 \mu \mathrm{W}$ at $10 \mathrm{~Gb} / \mathrm{s}, 40 \mathrm{~Gb} / \mathrm{s}$, $100 \mathrm{~Gb} / \mathrm{s}, 160 \mathrm{~Gb} / \mathrm{s}, 250 \mathrm{~Gb} / \mathrm{s}$ respectively at $50 \mathrm{~m}$ scattering section dispersion. While the electrical power is $2.352 \mu \mathrm{W}, 1.367 \mu \mathrm{W}, 1.322 \mu \mathrm{W}, 1.0765 \mu \mathrm{W}, 0.654 \mu \mathrm{W}$ at $10 \mathrm{~Gb} / \mathrm{s}, 40 \mathrm{~Gb} / \mathrm{s}, 100 \mathrm{~Gb} / \mathrm{s}, 160 \mathrm{~Gb} / \mathrm{s}, 250 \mathrm{~Gb} / \mathrm{s}$ respectively at $100 \mathrm{~m}$ scattering section dispersion. The electrical power is $2.35 \mu \mathrm{W}, 1.315 \mu \mathrm{W}, 1.297 \mu \mathrm{W}$, $1.0113 \mu \mathrm{W}, 0.527 \mu \mathrm{W}$ at $10 \mathrm{~Gb} / \mathrm{s}, 40 \mathrm{~Gb} / \mathrm{s}, 100 \mathrm{~Gb} / \mathrm{s}, 160 \mathrm{~Gb} / \mathrm{s}, 250 \mathrm{~Gb} / \mathrm{s}$ respectively at $150 \mathrm{~m}$ scattering section dispersion. Moreover the electrical power is $2.348 \mu \mathrm{W}, 1.286 \mu \mathrm{W}, 1.278167 \mu \mathrm{W}, 0.956583 \mu \mathrm{W}$, 
$0.354 \mu \mathrm{W}$ at $10 \mathrm{~Gb} / \mathrm{s}, 40 \mathrm{~Gb} / \mathrm{s}, 100 \mathrm{~Gb} / \mathrm{s}, 160 \mathrm{~Gb} / \mathrm{s}, 250 \mathrm{~Gb} / \mathrm{s}$ respectively at $200 \mathrm{~m}$ scattering section dispersion. The electrical power is $2.346 \mu \mathrm{W}, 1.282 \mu \mathrm{W}, 1.256667 \mu \mathrm{W}, 0.901833 \mu \mathrm{W}, 0.181 \mu \mathrm{W}$ at $10 \mathrm{~Gb} / \mathrm{s}$, $40 \mathrm{~Gb} / \mathrm{s}, 100 \mathrm{~Gb} / \mathrm{s}, 160 \mathrm{~Gb} / \mathrm{s}, 250 \mathrm{~Gb} / \mathrm{s}$ respectively at $250 \mathrm{~m}$ scattering section dispersion. The results emphasized that the higher the scattering section dispersion the slightly lower the electrical signal power at APD receiver.

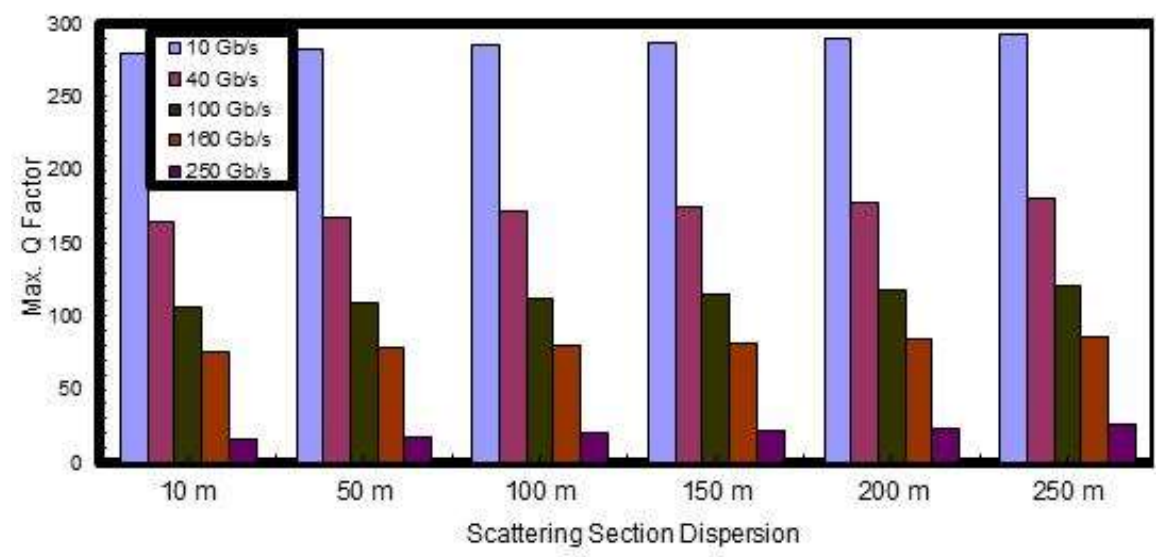

Figure 11. Max Q Factor variations versus scattering section dispersion variations for various data rates

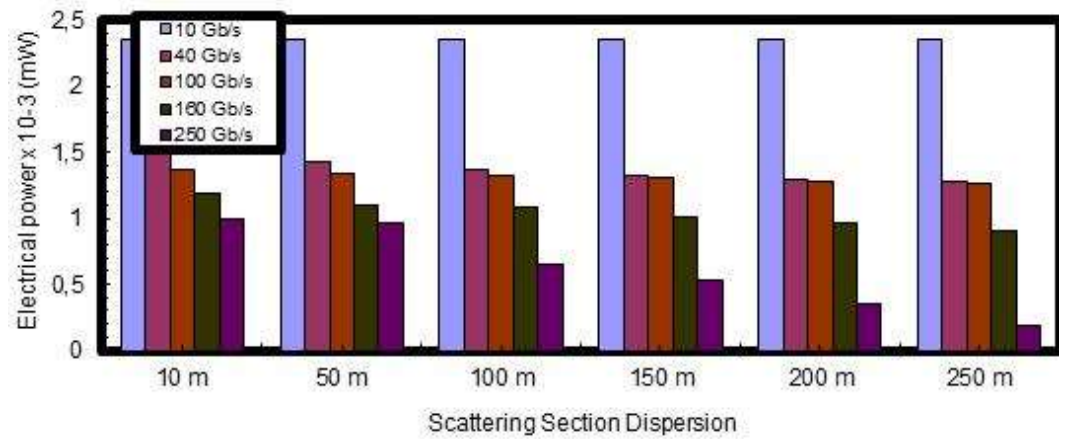

Figure 12. Electrical signal power after APD receiver variations versus scattering section dispersion variations for various data rates

\section{CONCLUSION}

The fixed scattering section length with variable scattering section dispersion have been simulated based optical fibers for polarization mode dispersion penalties at high data rates. The max $\mathrm{Q}$ factor, electrical power variations for various scattering section dispersion and data transmission rates have been clarified. The higher the scattering section dispersion the slightly lower the electrical signal power at APD receiver. It is emphasized that the higher the scattering section dispersion the high the max $\mathrm{Q}$ factor can be achieved. The max signal power/min noise power against time has been simulated after fiber length of $500 \mathrm{~km}$ with various scattering section dispersion. The higher the scattering section dispersion, the lower max signal power. So it is recommended to operate at $10 \mathrm{~m}$ scattering section dispersion with transmission rate of $40 \mathrm{Gbps}$.

\section{REFERENCES}

[1] J. Witzens, et al., "Design of Transmission Line Driven Slot Waveguide Mach-Zehnder Interferometers and Application to Analog Optical Links," Optics Express., vol. 18, no. 16, pp. 1603-1628, 2010.

[2] IS Amiri, et al., "Pump Laser Automatic Signal Control for Erbium-Doped Fiber Amplifier Gain, Noise Figure, and Output Spectral Power," Journal of Optical Communications, Published Online: 17 Dec. 2019, https://doi.org/10.1515/joc-2019-0203. 
[3] A. Chandra, et al., "Unified BER and Optimum Threshold Analysis of Binary Modulations in Simple and Cascaded Rayleigh Fading Channels With Switched Combining," International Journal of Communication Systems, vol. 24, no. 2, pp. 153-167, 2011.

[4] Q. TAO, et al., "Optical Switch Based on Cascaded SOI Nonlinear Directional Coupler," Optica Applicata, vol. 41, no. 3, pp. 669-678, 2011.

[5] T. Kawanishi, et al., "High Speed Control of Lightwave Amplitude, Phase, and Frequency by use of Electrooptic Effect," IEEE Journal of Selected Topics in Quantum Electronics, vol. 13, no. 1, pp. 79-91, 2007.

[6] H. V. Pham, et al., "Travelling Wave Electrooptic Modulators With Arbitrary Frequency Response Utilising Non Periodic Polarization Reversal," Electronics Letters, vol. 43, no. 24, pp. 1379-1381, 2007.

[7] William B. Bridges, James H. Schaffner, "Distortion in Linearized Electrooptic Modulators," IEEE Transactions on Microwave Theory and Techniques, vol. 43, no. 9, 1995.

[8] Ahmed Nabih Zaki Rashed, Mohammed Salah F. Tabbour "Suitable Optical Fiber Communication Channel for Optical Nonlinearity Signal Processing in High Optical Data Rate Systems" Wireless Personal Communications Journal, Springer Publisher, Published online 24 May 2017, vol. 97, no. 1, pp. 397-416, 2017.

[9] Ahmed Nabih Zaki Rashed, et al., "Optimum Flat Gain With Optical Amplification Technique Based on Both Gain Flattening Filters and Fiber Bragg Grating Methods," Journal of Nanoelectronics and Optoelectronics, vol. 13, no. 5, pp. 665-676, 2018.

[10] Ahmed Nabih Zaki Rashed, Mohammed Salah F. Tabbour "The Trade Off Between Different Modulation Schemes for Maximum Long Reach High Data Transmission Capacity Optical Orthogonal Frequency Division Multiplexing (OOFDM)" Wireless Personal Communications Journal, Springer Publisher, Published online 14 May 2018, https://doi.org/10.1007/s11277-018-5690-9, vol. 101, no. 1, pp. 325-337, 2018.

[11] S. Praveen Chakkravarthy, et al., "Ultra high transmission capacity based on optical first order soliton propagation systems," Results in Physics, vol. 12, pp. 512-513, 2019.

[12] H. V. Pham, and Y. Okamura, "Electrooptic Modulators with Controlled Frequency Responses by Using Nonperiodically Polarization Reversed Structure," Journal of Advances in Optoelectronics, vol. 8, no. 1, pp. 1-8, 2008.

[13] Min Chen, et al., "Advances in Multimedia Communications," International Journal of Communication Systems, vol. 24, no. 10, pp. 1243-1245, 2011.

[14] A. Maksymiuk, and J. Siuzdak, "Modeling of Low Frequency Modal Noise Induced by Multimode Couplers in Cascade Connections," Optica Applicata, vol. 41, no. 3, pp. 649-660, 2011.

[15] F. T. Sheehy, et al., "94 GHz Antenna-coupled LiNbO3 Electrooptic Modulators," IEEE Photonics Technology Letters, vol. 5, pp 307-310, 1993.

[16] Ahmed Nabih Zaki Rashed, et al., "The switching of optoelectronics to full optical computing operations based on nonlinear metamaterials," Results in Physics, Vol. 13, Article 102152, June 2019, https://doi.org/10.1016/j.rinp.2019.02.088.

[17] IS Amiri, et al., "The Engagement of Hybrid Ultra High Space Division Multiplexing with Maximum Time Division Multiplexing Techniques for High-Speed Single-Mode Fiber Cable Systems," Journal of Optical Communications, Published Online: 19 Oct. 2019, https://doi.org/10.1515/joc-2019-0205.

[18] IS Amiri, et al., "Polar Polarization Mode and Average Radical Flux Intensity Measurements Based on All Optical Spatial Communication Systems," Journal of Optical Communications, Published Online: 19 Oct. 2019, https://doi.org/10.1515/joc-2019-0159.

[19] L.M. Johnson, H. V. Roussell, "Reduction of Intermodulation distortion in Interferometric Optical Modulators," Optics Letters, vol. 13, no. 10, 1988.

[20] M. V. Raghavendra, P. H. Prasad, "Estimation of Optical Link Length for Multi Haul Applications," International Journal of Engineering Science and Technology, vol. 2, no.6, pp. 1485-1491, 2010.

[21] Ahmed Nabih Zaki Rashed, et al., "Rapid Progress of A Thermal Arrayed Waveguide Grating Module for Dense Wavelength Division Multiplexing Applications," International Journal of Advanced Networks and Applications, vol. 3, no. 2, pp. 1044-1052, 2011.

[22] S. Sivaranjani, et al., "Performance Evaluation of Bidirectional Wavelength Division Multiple Access Broadband Optical Passive Elastic Networks Operation Efficiency," Journal of Optical Communications, Published Online: 24 Oct. 2019, https://doi.org/10.1515/joc-2019-0175.

[23] IS Amiri, et al., "High-Speed Transmission Circuits Signaling in Optical Communication Systems," Journal of Optical Communications, Published Online: 9 Nov. 2019, https://doi.org/10.1515/joc-2019-0197.

[24] IS Amiri, et al., "Technical Specifications of the Submarine Fiber Optic Channel Bandwidth/Capacity in Optical Fiber Transmission Systems," Journal of Optical Communications, Published Online: 9 Nov. 2019, https://doi.org/10.1515/joc-2019-0226.

[25] M. Ghanbarisabagh, et al., "Cyclic Prefix Reduction for 20.48 Gb/s Direct Detection Optical OFDM Transmission over 2560 km of SSMF," International Journal of Communication Systems, Vol. 24, No. 11, pp. 1407-1417, 2011.

[26] H. Hu, et al., "Lithium Niobate Ridge Waveguides Fabricated by Wet Etching," IEEE Photonics Technology Letters, vol. 19, no. 6, pp. 417-419, 2007.

[27] A. Kozanecka, et al., "Electro Optic Activity of an Azopolymer Achieved Via Poling With the Aid of Silicon Nitride Insulating Layer," Optica Applicata, vol. 41, no. 3, pp. 777-785, 2011.

[28] Steven K. Korotky, René M. De Ridder, "Dual Parallel Modulation Schemes for Low-Distortion Analog Optical Transmission," IEEE Journal on Selected Areas in Communications, vol. 8, no. 7, 1990. 
[29] J. F. Lam and G. L. Tangonan, "Optical modulation system with enhanced linearization properties," IEEE Photon. Technol. Lett., Vol. 3, No. 12, pp. 1102-1104, 1991.

[30] IS Amiri, et al., "Influence of device to device interconnection elements on the system behavior and stability," Indonesian Journal of Electrical Engineering and Computer Science, vol. 18, no. 2, pp. 843-847, 2020, DOI: 10.11591/ijeecs.v18.i2.pp843-847.

[31] Mahmoud M. A. Eid, et al., "Dental lasers applications in visible wavelength operational band," Indonesian Journal of Electrical Engineering and Computer Science, vol. 18, no. 2, pp. 890-895, 2020, DOI: 10.11591/ijeecs.v18.i2.pp890-895.

[32] IS Amiri, et al., "Comparative Simulation Study of Multi Stage Hybrid All Optical Fiber Amplifiers in Optical Communications," Journal of Optical Communications, vol. 0, no. 0, Published Online: 4 Feb. 2020, https://doi.org/10.1515/joc-2019-0132.

[33] IS Amiri, et al., "Optical Communication Transmission Systems Improvement Based on Chromatic and Polarization Mode Dispersion Compensation Simulation Management," Published online 23 November 2019, Optik Journal, Vol. 207, article163853, April 2020, https://doi.org/10.1016/j.ijleo.2019.163853.

[34] D. Samanta, et al., "Distributed Feedback Laser (DFB) for Signal Power Amplitude Level Improvement in Long Spectral Band," Journal of Optical Communications, Vol. 0, Issue 0, Published Online: 2 April 2020, https://doi.org/10.1515/joc-2019-0252.

[35] IS Amiri, et al., "Analytical Model Analysis of Reflection/Transmission Characteristics of Long-Period Fiber Bragg Grating (LPFBG) by Using Coupled Mode Theory," Journal of Optical Communications, Vol. 0, Issue 0, Published Online: 2 April 2020, https://doiorg/10.1515/joc-2019-0187. 